\title{
Pathways for glutamate biosynthesis in the yeast Kluyveromyces lactis
}

\author{
Mauricio Romero, Simón Guzmán-León, Cristina Aranda, \\ Diego González-Halphen, Lourdes Valenzuela \\ and Alicia González
}

\author{
Author for correspondence: Alicia González. Tel: +52 562256 31. Fax: +52 56225630. \\ e-mail: amanjarr@ifisiol.unam.mx
}

Departamento de Genética Molecular, Instituto de Fisiología Celular, Universidad Nacional Autónoma de México, Apartado Postal 70-242, 04510 Mexico City, Mexico

\begin{abstract}
Purified glutamate synthase (GOGAT) from Kluyveromyces lactis was characterized as a high-molecular-mass polypeptide, a distinction shared with previously described GOGATs from other eukaryotic micro-organisms. Using degenerate deoxyoligonucleotides, designed from conserved regions of the alfalfa, maize and Escherichia coli GOGAT genes, a 300 bp PCR fragment from the $K$. lactis GOGAT gene KIGLT1 was obtained. This fragment was used to construct null GOGAT mutants of $K$. lactis by gene replacement. These mutants showed no growth defect phenotype and were able to grow on ammonium as sole nitrogen source. Double mutants obtained from a cross between a previously described KIGDH1 mutant and the $K$. lactis null GOGAT strain were full glutamate auxotrophs. These results indicate that glutamate biosynthesis in $K$. lactis is afforded through the combined action of KIGDH1 and KIGLT1 products.
\end{abstract}

Keywords: glutamate biosynthesis, glutamate synthase, glutamate dehydrogenase

\section{INTRODUCTION}

Two pathways for ammonium assimilation and glutamate biosynthesis have been found in a variety of micro-organisms. The first one, described by Holzer \& Schneider (1957), is mediated by NADP-glutamate dehydrogenase (NADP-GDH; EC 1.4.1.4), which catalyses the reductive amination of 2-oxoglutarate to form glutamate. In an alternative pathway demonstrated by Tempest $e t$ al. (1970), glutamate is aminated to form glutamine by glutamine synthetase (GS; EC 6.3.1.2), the amide group of which is then transferred reductively to 2-oxoglutarate by glutamate synthase (GOGAT; EC 1.4.1.13), resulting in the net conversion of ammonium and 2-oxoglutarate to glutamate. The GS-GOGAT pathway has been found in several micro-organisms (Senior, 1975; Hummelt \& Mora, 1980; Bravo \& Mora, 1988; Marqués et al., 1992) and in higher plants (Miflin et al., 1980).

Mutants affected in either NADP-GDH or GOGAT have been obtained in a number of fungal species. In the yeast Saccharomyces cerevisiae, besides the GS-GOGAT

Abbreviations: GDH, glutamate dehydrogenase; GOGAT, glutamate synthase; GS, glutamine synthetase. pathway, there are two NADP-GDH isozymes, NADPGDH1 and NADP-GDH3, encoded by GDH1 and GDH3, respectively (Avendaño et al., 1997). In this yeast, only the triple mutant lacking GOGAT, GDH1 and GDH3 shows a tight glutamate auxotrophy (Avendaño et al., 1997). In Neurospora crassa and Aspergillus nidulans, the simultaneous lack of GOGAT and NADP-GDH leads to full auxotrophy, indicating that in this species, only two pathways for glutamate biosynthesis are functional (Romero \& Dávila, 1986; Macheda et al., 1999). Thus, S. cerevisiae is so far the only example of a micro-organism possessing three pathways for glutamate biosynthesis.

In Kluyveromyces lactis, both NADP-GDH and GOGAT activities have been detected (Valenzuela et al., 1995). Mutants devoid of NADP-GDH showed a wildtype phenotype, suggesting that either the GS-GOGAT pathway plays a major role in glutamate biosynthesis or that, as found for $S$. cerevisiae gdh1 mutants, glutamate biosynthesis could be maintained by the combined action of the GS-GOGAT pathway and a third biosynthetic route. To analyse this matter, we isolated a $K$. lactis single mutant impaired in GOGAT activity and a double mutant lacking both GOGAT and NADP-GDH. The first mutant strain did not display any growth defect phenotype whilst the double mutant was a full glutamate auxotroph. This implies that, as in $N$. crassa and $A$. 
nidulans, K. lactis has only two pathways for glutamate biosynthesis.

\section{METHODS}

Growth conditions. K. lactis MD2/1 (MAT $\alpha \arg A$ lys A uraA) and WM37 (MATa his3) were grown on minimal medium (MM) containing salts, trace elements and vitamins following the formula of the yeast nitrogen base (Difco). Glucose $(2 \%$, $\mathrm{w} / \mathrm{v})$ was used as the carbon source and $38 \mathrm{mM}\left(\mathrm{NH}_{4}\right)_{2} \mathrm{SO}_{4}$ as the nitrogen source. Auxotrophic requirements were added at $0.01 \%(\mathrm{w} / \mathrm{v})$ and cells were incubated at $30{ }^{\circ} \mathrm{C}$ with agitation. Growth was monitored by measuring optical density at 600 nm. (Hewlett Packard model 8452A spectrophotometer). Yeast extract/peptone/dextrose (YPD) plates contained $2 \%$ glucose, $1 \%$ yeast extract (Difco), $2 \%$ peptone (Difco) and $2 \%$ agar (Difco).

Determination of GOGAT and NADP-GDH activities. Soluble extracts for enzyme assays were prepared as previously described (Valenzuela et al., 1995). NADP-GDH and GOGAT were assayed by the methods of Doherty (1970) and Roon et al. (1974), respectively. Protein was measured by the Lowry method with bovine serum albumin as a standard.

Purification of GOGAT from $\boldsymbol{K}$. lactis. $K$. lactis MD2/1 was grown in $121 \mathrm{MM}$, harvested at an $\mathrm{OD}_{600}$ of 0.5 and stored at $-70{ }^{\circ} \mathrm{C}$ until used. All purification steps were carried out at $4{ }^{\circ} \mathrm{C}$.

Step 1: crude extract. Cells were thawed and resuspended in $2 \mathrm{ml}$ buffer A $[0 \cdot 1 \mathrm{M}$ potassium phosphate $(\mathrm{pH} 7 \cdot 5), 1 \mathrm{mM}$

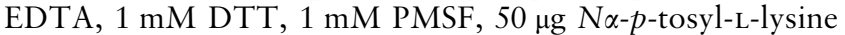
chloromethyl ketone (TLCK) $\mathrm{ml}^{-1}$ and $100 \mu \mathrm{g} N$-tosyl-Lphenylalanine chloromethyl ketone (TPCK) $\left.\mathrm{ml}^{-1}\right](\mathrm{g} \text { cells })^{-1}$. Crude extracts were obtained after mechanical disruption of cells with a Bead-Beater (10 cycles of $1 \mathrm{~min}$ ), using $0.5 \mathrm{~g}$ $710-180 \mu \mathrm{m}$ diameter glass beads ( $\mathrm{ml}$ cell suspension $)^{-1}$ and centrifugation at $35000 \mathrm{~g}$ for $30 \mathrm{~min}$.

Step 2: ammonium sulphate precipitation. Crude extract was treated with a saturated solution of ammonium sulphate $(\mathrm{pH}$ $7 \cdot 5)$. Proteins precipitating at $30 \%$ saturation were discarded and the supernatant was dialysed four times (30 min each) against 21 buffer A but lacking DTT and protease inhibitors (buffer B).

Step 3: affinity chromatography. The dialysed fraction was applied to a $40 \mathrm{ml}$ blue Sepharose column $(23 \times 1.7 \mathrm{~cm})$ previously equilibrated with buffer A plus $0.2 \mathrm{mM} 2$-oxoglutarate and $5 \%$ glycerol (buffer C). After sample application, the column was washed with 20 column volumes of buffer $\mathrm{C}$ and GOGAT activity was eluted with buffer $\mathrm{C}$ that also contained $0 \cdot 1 \mathrm{mM}$ NADH. Fractions with GOGAT activity were pooled and dialysed three times against buffer B for $30 \mathrm{~min}$; protease inhibitors $\left(0.5 \mathrm{mM} \mathrm{DTT}, 25 \mu \mathrm{g} \mathrm{ml} \mathrm{m}^{-1}\right.$ TLCK, $50 \mu \mathrm{g} \mathrm{ml}^{-1}$ TPCK and 0.05 mM PMSF) were added and protein was concentrated by ultrafiltration using an Amicon YM30 membrane.

Molecular mass determination. The apparent molecular mass of the GOGAT polypeptide was determined by SDS-PAGE (Schägger et al., 1986). Molecular mass standards were obtained from Sigma.

Western blot analysis. Immunoblotting was carried out as described by Towbin et al. (1979), with the modifications of González-Halphen et al. (1988). S. cerevisiae GOGAT antiserum, obtained as described by Cogoni et al. (1995), was diluted 1:50000 and goat anti-rabbit immunoglobulin Galkaline phosphatase conjugate was used as the secondary antibody.

Northern analysis. Northern analysis was carried out as previously described (González et al., 1992). Total RNA of the MD2/1 wild-type strain was prepared from $50 \mathrm{ml}$ of overnight cultures in MM, as described by Struhl \& Davis (1981). Prehybridization was carried out at $65^{\circ} \mathrm{C}$ for $60 \mathrm{~min}$ and hybridization was carried out at $65^{\circ} \mathrm{C}$ for $12 \mathrm{~h}$. Filters were first washed with a tenfold dilution of $20 \times$ SSC (Maniatis et al., 1982) containing $0 \cdot 10 \%$ SDS at $65^{\circ} \mathrm{C}$ for $30 \mathrm{~min}$ and then with a 130 -fold dilution of $20 \times$ SSC containing $0 \cdot 10 \%$ SDS at $65^{\circ} \mathrm{C}$ for $30 \mathrm{~min}$.

Southern analysis. Southern analysis was carried out as described by Nasmyth \& Reed (1980). Total K. lactis DNA was prepared from $50 \mathrm{ml}$ of overnight cultures of the MD2/1 wild-type strain or of the WM37 glt1 mutant in MM. When a heterologous probe was used, prehybridization was carried out at $45^{\circ} \mathrm{C}$ for $45 \mathrm{~min}$ and hybridization was carried out at $45^{\circ} \mathrm{C}$ for $24 \mathrm{~h}$. Filters were washed twice with a tenfold dilution of $20 \times$ SSC containing $0 \cdot 10 \%$ SDS at $45^{\circ} \mathrm{C}$ for $35 \mathrm{~min}$. When an homologous probe was used, prehybridization and hybridization conditions were those described for the Northern analysis.

PCR amplification. K. lactis GLT1 (GOGAT) PCR amplification was conducted using the deoxyoligonucleotides and the programme described by Cogoni et al. (1995). Total DNA from $K$. lactis strain WM37 was used as template for amplification by PCR in a Stratagene Robocycler 40. The amplification product ( $300 \mathrm{bp}$ as judged on agarose gel) was cloned in the EcoRI restriction site of the Stratagene SK plasmid and sequenced with an ABI PRISM Genetic Analyzer, using the ABI PRISM Big Dye Terminator Cycle Sequencing Ready Reaction Kit from Applied Biosystems-Perkin Elmer. To obtain a PCR product suitable for gene disruption, the PCR-based ORF replacement protocol described by Wach et al. (1994) was used with kanMX as a marker. Two deoxyoligonucleotides were designed based on the nucleotide sequence of the K. lactis GOGAT fragment obtained by PCR and on the sequence of the multiple cloning site present in the pFA6a vector (Wach et al., 1994). The deoxyoligonucleotide S1 (5'-GAG ACT CAT CAA ACA TTA GTT TTG AAT GAT TTG AGA GGA AAC GTC CGT ACG CTG CAG GTC GAC-3') comprises 45 bp from the most $5^{\prime}$ end of the $K$. lactis PCR GOGAT fragment and $18 \mathrm{bp}$ (indicated above in bold lettering) of the pFA6a multiple cloning site. The deoxyoligonucleotide S2 (5'-GAA TTT GTC TCT CAA AAC GGG GTC TTG AGT GGC AAT ACC AAC TGC ATC GAT GAA TTC GAG CTC G-3') contains 45 bp from the $3^{\prime}$ end of the PCR GOGAT fragment and $19 \mathrm{bp}$ (bold) from the pFA6a multiple cloning site. Qiagen purified pFA6a DNA was used as template for amplification by PCR, carried out in a Stratagene Robocycler 40 with the following programme: one denaturing cycle for $30 \mathrm{~s}$ at $94^{\circ} \mathrm{C}$, followed by 26 cycles of $30 \mathrm{~s}$ denaturation at $94{ }^{\circ} \mathrm{C}, 1 \mathrm{~min}$ annealing at $50{ }^{\circ} \mathrm{C}$ and $3 \mathrm{~min}$ extension at $72^{\circ} \mathrm{C}$. A 1500 bp PCR product obtained was gelpurified and used to transform strain WM37.

\section{RESULTS AND DISCUSSION}

\section{K. lactis GOGAT purification}

GOGAT was purified from $K$. lactis strain MD2/1 by classical chromatographic methods. A $0.6 \%$ yield and a 1000 -fold increase in specific activity were attained 
Table 1. Purification of $K$. lactis NADH-GOGAT

From 6 g wet weight cells.

\begin{tabular}{|c|c|c|c|c|c|}
\hline $\begin{array}{l}\text { Purification } \\
\text { step }\end{array}$ & $\begin{array}{l}\text { Total protein } \\
\qquad(\mathbf{m g})\end{array}$ & 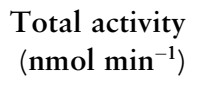 & $\begin{array}{l}\text { Specific activity } \\
\left(\mathrm{nmol} \mathrm{min}^{-1} \mathrm{mg}^{-1}\right)\end{array}$ & $\begin{array}{l}\text { Yield } \\
(\%)\end{array}$ & $\begin{array}{l}\text { Purification } \\
\text { factor* }\end{array}$ \\
\hline Crude extract & 170 & 1340 & 8 & 100 & 1 \\
\hline $\begin{array}{l}30 \%\left(\mathrm{NH}_{4}\right)_{2} \mathrm{SO}_{4} \\
\text { supernatant }\end{array}$ & 121 & 950 & 8 & 71 & 1 \\
\hline Blue Sepharose & $0 \cdot 001$ & 8 & 8000 & $0 \cdot 6$ & 1000 \\
\hline
\end{tabular}

*Fold increase in specific activity.

(a)

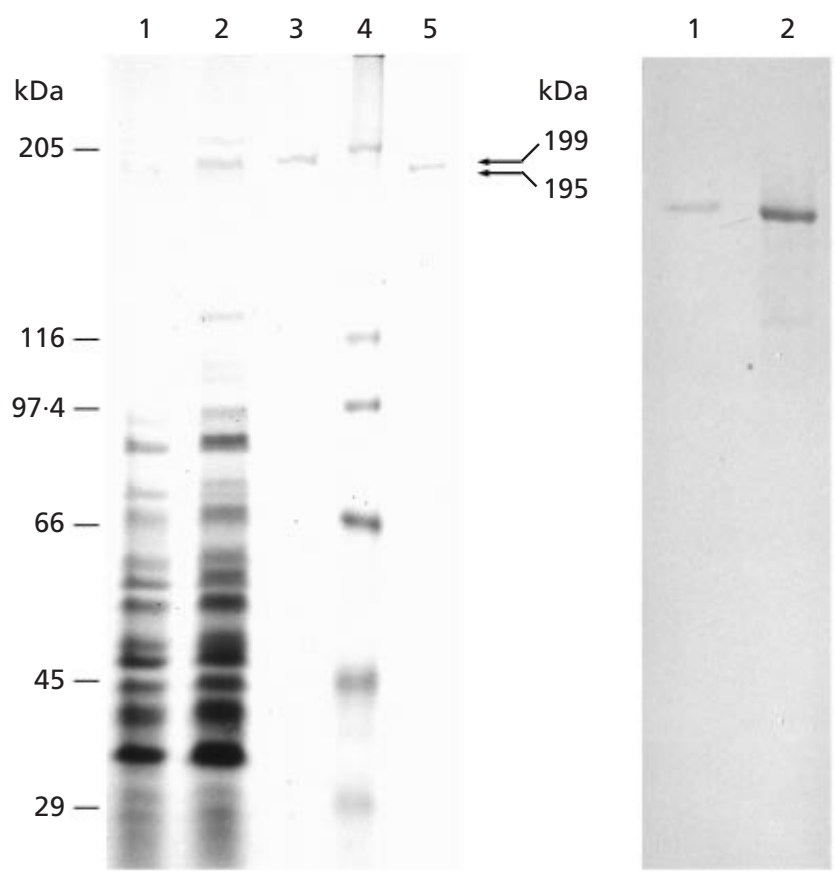

Fig. 1. (a) SDS-6\% PAGE of the main fractions obtained during purification of $K$. lactis GOGAT. Lanes: 1 , crude extract $(50 \mu \mathrm{g})$; 2 , supernatant obtained after ammonium sulphate precipitation $(30 \%)(50 \mu \mathrm{g}) ; 3$, fraction from blue Sepharose (40 ng); 4, molecular mass standards (myosin, $205 \mathrm{kDa} ; \beta$ galactosidase, $116 \mathrm{kDa}$; phosphorylase $b, 97.4 \mathrm{kDa}$; bovine serum albumin, $66 \mathrm{kDa}$; ovalbumin, $45 \mathrm{kDa}$; and carbonic anhydrase, $29 \mathrm{kDa}$ ); 5, pure GOGAT from S. cerevisiae (Cogoni et al., 1995). Proteins were visualized by Coomassie blue staining. (b) Western blot with antibodies raised against GOGAT from $S$. cerevisiae. GOGAT antiserum was probed against $40 \mathrm{ng}$ purified $K$. lactis GOGAT (lane 1) and $250 \mathrm{ng}$ purified S. cerevisiae GOGAT (lane 2).

(Table 1). The yields and final specific activities are comparable with those obtained for GOGAT purification from S. cerevisiae (Cogoni et al., 1995). SDSPAGE analysis of the fractions obtained throughout purification is shown in Fig. 1(a). Purification of the $K$. lactis GOGAT followed the procedure used to purify the $S$. cerevisiae enzyme (Cogoni et al., 1995) except that ion-exchange using DEAE-Biogel $\mathrm{A}$ and the hydrophobic chromatography steps were omitted. The $K$. lactis protein so obtained was readily degradable. To avoid degradation, the mixture of protease inhibitors described in Methods was included in all steps. A homogeneous fraction was obtained by applying the supernatant from the ammonium sulphate precipitation to a blue Sepharose column (Fig. 1a). This result suggests that $K$. lactis GOGAT comprises a single highmolecular-mass polypeptide, the possible multimeric association of which remains to be established.

Being a high-molecular-mass polypeptide, the NADHGOGAT from $K$. lactis is similar to the GOGAT enzymes of other fungi and of higher plants (Hummelt \& Mora, 1980; Anderson et al., 1989; Cogoni et al., 1995), and different to the dimeric enzymes composed of small and large subunits found in all the prokaryotic micro-organisms so far analysed (Miller \& Stadtman, 1972; Trotta et al., 1974; Adachi \& Suzuki, 1977; Schreier \& Bernlohr, 1984; Ratti et al., 1985; Vanoni et al., 1990; Carlberg \& Nordlund, 1991).

The apparent molecular mass of the pure polypeptide was $199 \mathrm{kDa}$, as estimated by SDS-PAGE. This value is comparable to those of $S$. cerevisiae, $N$. crassa and plant NADH-GOGAT (Hummelt \& Mora, 1980; Benny \& Bolland, 1977; Chen \& Cullimore, 1988: Hayakawa et al., 1992; Anderson et al., 1989; Cogoni et al., 1995).

Western blot analysis was carried out with antibodies raised against the $S$. cerevisiae GOGAT protein (Cogoni et al., 1995). These antibodies cross-reacted with crude extracts (data not shown) and pure GOGAT protein from $K$. lactis (Fig. 1b), suggesting that these two proteins bear similar antigenic epitopes. The same antibodies did not react with Escherichia coli NADPHGOGAT (Cogoni et al., 1995).

Since the immunoblotting results suggested similarity between the S. cerevisiae and K. lactis GOGAT enzymes, we decided to use an internal EcoRI-EcoRI $4.3 \mathrm{~kb}$ fragment of the $S$. cerevisiae GOGAT gene (Cogoni et al., 1995) as a hybridization probe against total DNA from $K$. lactis strain MD2/1. Using low-stringency hybridizing conditions we were able to detect an EcoRI-EcoRI $4.3 \mathrm{~kb}$ band in total DNA of K. lactis 
(a)

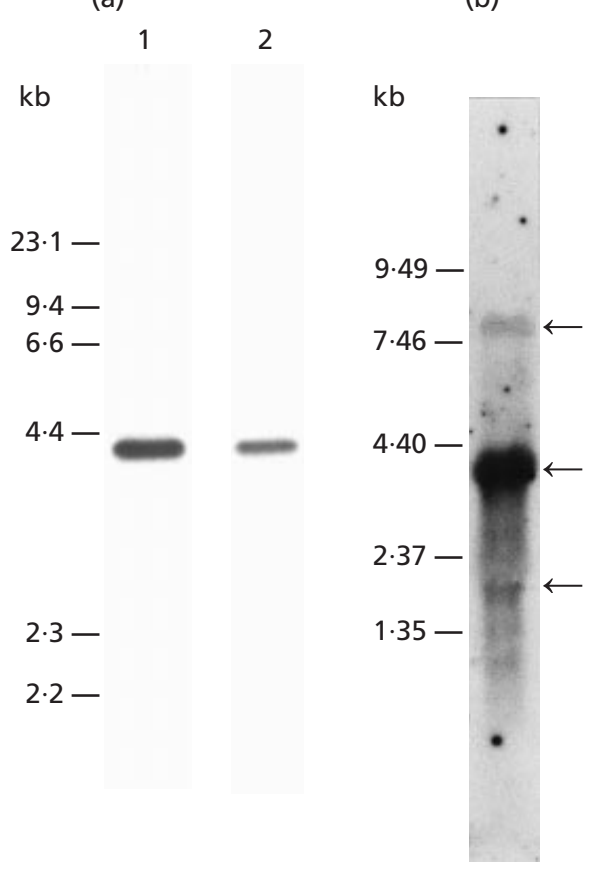

Fig. 2. (a) Southern blot of $K$. lactis total DNA digested with EcoRI. A $4.3 \mathrm{~kb}$ EcoRI-EcoRI fragment of $S$. cerevisiae GOGAT (Cogoni et al., 1995) labelled with $\left[\alpha^{32} P\right] C T P$ was used as probe. Lanes: 1 , S. cerevisiae DNA; $2, K$. lactis DNA. Pointers on the left indicate the migration positions of lambda Hindlll-digested DNA. (b) Northern blot of total RNA from $K$. lactis. RNA sample (10 mg) was separated by electrophoresis on a denaturing $1 \%$ agarose gel and transferred to a Hybond-N filter (see Methods). The filter was probed with a $300 \mathrm{bp}$ internal PCR fragment of the $K$. lactis GOGAT gene. Arrows on the right indicate the migration positions of GOGAT mRNA, 25S rRNA and 16S rRNA from top to bottom, respectively. Pointers on the left indicate the migration positions of a 1.35-9.49 kb RNA ladder from Gibco-BRL.

digested with EcoRI (Fig. 2a). This result suggested that the $K$. lactis genome contained a sequence homologous to the $S$. cerevisiae GOGAT probe used.

To obtain an homologous K. lactis GOGAT fragment, PCR amplification of $K$. lactis genomic DNA was performed as described in Methods, using two deoxyoligonucleotides derived from the central region of the alfalfa GOGAT gene, those previously utilized to amplify a GOGAT fragment from S. cerevisiae (Cogoni et al., 1995). The PCR product was subcloned into the SK vector and sequenced. The deduced amino acid sequence showed $92 \%$ identity with the corresponding region of the GOGAT protein of $S$. cerevisiae (data not shown).

To determine the size of the mRNA that encodes the $K$. lactis GOGAT, the $300 \mathrm{bp}$ PCR product was hybridized against total RNA extracted from the K. lactis wild-type strain (MD2/1). As shown in Fig. 2(b), a major band of around 7 or $8 \mathrm{~kb}$ was identified. These results indicate that the GOGAT enzyme from $K$. lactis should be constituted by a high-molecular-mass polypeptide. In

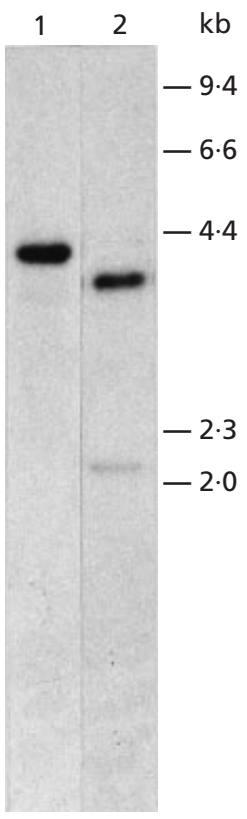

Fig. 3. Southern analysis of $K$. lactis DNA digested with $B g / l l$. Lanes: 1, wild-type strain WM37; 2, mutant strain WM37a. The blot was probed with a $300 \mathrm{bp}$ internal PCR fragment of the $K$. lactis GOGAT gene. Pointers on the right indicate the migration positions of lambda HindIII-digested DNA.

order to analyse whether the $199 \mathrm{kDa}$ polypeptide was the only GOGAT in K. lactis we decided to disrupt the KlGLT1 gene that encodes this protein.

To obtain a null GOGAT mutant, the PCR product flanked by GLT1 sequences, obtained as described in Methods, was used to transform strain WM37, following the lithium acetate protocol described by Gietz \& Woods (1994). After transformation, cells were allowed to grow for $3 \mathrm{~h}$ in liquid YPD (see Methods). Transformation mix was then plated on YPD plates containing $200 \mathrm{mg} \mathrm{G} 418 \mathrm{l}^{-1}$. After $3 \mathrm{~d}$ incubation, four colonies appeared on the transformation plates. These were streaked out on YPD/G418 plates and three of them (WM37a, WM37b and WM37c) grew out to form single colonies. Chromosomal DNA was isolated from the three transformants and digested with BglII. Southern analysis was carried out with the $300 \mathrm{bp}$ PCR fragment as the probe. The pattern obtained from the transformants clearly indicated the insertion of the construct in the wild-type genomic sequence of KlGLT1 (Fig. 3). The null mutants were completely devoid of GOGAT activity (Table 2).

\section{Isolation and characterization of a double mutant devoid of NADP-GDH and GOGAT activities}

To isolate a double mutant impaired both in KlGDH1 and in KlGLT1, strains JR1 (MATa lysA $\arg A$ gdh1::uraA) and WM37a (MATa his3 glt1::kanMX) 
Table 2. NADP-GDH and GOGAT specific activities

Cells were grown to an $\mathrm{OD}_{600}$ of 0.7 with $38 \mathrm{mM}\left(\mathrm{NH}_{4}\right)_{2} \mathrm{SO}_{4}$ except for strain $\mathrm{C} 4 \mathrm{~A}$, which was grown on $7 \mathrm{mM}$ glutamate without $\left(\mathrm{NH}_{4}\right)_{2} \mathrm{SO}_{4}$.

\begin{tabular}{|lcc|}
\hline Strain (relevant genotype) & NADP-GDH* & GOGAT $\dagger$ \\
\hline WM37 (GDH1 GLT1) & 500 & 12 \\
WM37a (GDH1 glt1) & 450 & ND \\
MD2/1 (GDH1 GLT1) & 530 & 13 \\
JR1 (gdh1 GLT1) & ND & 39 \\
C4A (gdh1 glt1) & ND & ND \\
\hline
\end{tabular}

ND, Not detected.

*Expressed as nmol NADPH oxidized $\min ^{-1}$ (mg protein $)^{-1}$. The reported values are the means of three experiments; variation was $5-10 \%$.

†Expressed as nmol NADH oxidized $\min ^{-1}$ (mg protein $)^{-1}$. The reported values are the means of three experiments; variation was $5-10 \%$.

were crossed and random spore analysis was performed. One quarter of the analysed population was unable to grow on $\mathrm{MM}$ in the presence of ammonium as sole nitrogen source, but recovered wild-type growth when $0.05 \%$ glutamate was added to the medium.

Table 2 shows that when grown on glutamate, the double mutant C4A showed neither NADP-GDH nor GOGAT activity. As can be seen in Fig. 4, single GOGAT null mutants grew as well as the wild-type strain on ammonium as sole nitrogen source. However the double mutant $(\mathrm{C} 4 \mathrm{~A})$ was completely unable to grow in the absence of glutamate. These results show that in $K$. lactis two pathways exist for glutamate biosynthesis and that both of them have to be knocked out in order to obtain a glutamate auxotroph.

The presence of two pathways for glutamate biosynthesis in several micro-organisms has stimulated discussion on the need for two routes for the biosynthesis of the same end product. The role of these two pathways has been clearly elucidated in Klebsiella aerogenes. In this bacterium, the GS-GOGAT pathway functions to assimilate ammonium and synthesize glutamate when the ammonium concentration is low, whilst GDH plays this role when the cells are cultivated under ammonium excess (Senior, 1975). In E. coli, GDH and GOGAT are simultaneously present and this raises the issue of their relative contributions to glutamate synthesis. Neither GDH- nor GOGAT-deficient strains have an observable growth defect when these strains are grown under ammonium excess or ammonium limitation, nor in energy-rich media (Tyler, 1978). However, it has been shown that E. coli gdhA mutant strains are at a competitive disadvantage relative to wild-type strains in carbon- and energy-limited media. These results suggest that GDH is important for glutamate synthesis during energy-limited growth and that GOGAT is the primary enzyme for glutamate biosynthesis during growth in energy-rich medium (Helling, 1994). In N. crassa, GOGAT has an important role recycling organic nitrogen from glutamine and glutamate; however, both GDH and GOGAT are involved in glutamate synthesis under ammonium excess or limitation (Hummelt \& Mora. 1980). The roles of GDH and GOGAT have been studied in some yeasts. In Schizosaccharomyces pombe and Candida albicans, evidence indicates that the GSGOGAT pathway is the major pathway for ammonium assimilation (Barel \& MacDonald, 1993; Holmes et al., 1989). S. cerevisiae constitutes the only example in which three pathways take over glutamate biosynthesis (NADP-GDH1, NADP-GDH3 and GOGAT) (Avendaño et al., 1997), and it has been proposed that GOGAT plays an important role furnishing glutamate during amino acid deprivation; however, when this organism is grown under either ammonium excess or limitation, glutamate biosynthesis is mainly achieved through GDH1 and GOGAT (Valenzuela et al., 1998). The role of NADP-GDH3 in glutamate biosynthesis is yet to be determined.

$K$. lactis mutants devoid of NADP-GDH, showed no growth defect phenotype. Since these mutant strains have increased GS and GOGAT activities, it has been suggested that in this yeast the GS-GOGAT pathway could constitute either the major pathway for ammonium assimilation or a compensatory mechanism for the lack of NADP-GDH (Valenzuela et al., 1995). The isolation of $K$. lactis null GOGAT mutants has allowed us to show that, similar to the situation occurring in $E$. coli, neither null NADP-GDH mutants nor GOGAT null mutants exhibit a growth defect phenotype. Further experiments will have to be conducted in order to determine whether there are particular physiological conditions in which each of the two pathways present in $K$. lactis plays a major biosynthetic role. As has been pointed out previously, Schizosaccharomyces pombe mutants devoid of GOGAT activity grow slowly and show a fivefold increase in their NADP-GDH levels, implying that the GS-GOGAT pathway is the primary route of glutamate biosynthesis (Barel \& MacDonald, 1993). Thus, the primary route for glutamate biosynthesis is not the same in all yeast species, although so far all the species studied have both GDH and GOGAT enzymes.

As mentioned earlier, besides GOGAT, S. cerevisiae has two non-allelic genes encoding two different NADPGDH isozymes, one of which most probably evolved as the result of duplication of a primary gene. In this regard, it has been proposed (Wolfe \& Shields, 1997), that $S$. cerevisiae is a degenerate tetraploid resulting from whole-genome duplication, and that Kluyveromyces and Saccharomyces diverged before this proposed genome duplication of S. cerevisiae occurred. Accordingly, it has been found that Kluyveromyces homologues of many $S$. cerevisiae genes are only found in single copy. This study shows that $K$. lactis has a single copy of the NADP-GDH-encoding genes, thus constituting another example of genes that were duplicated sometime during 


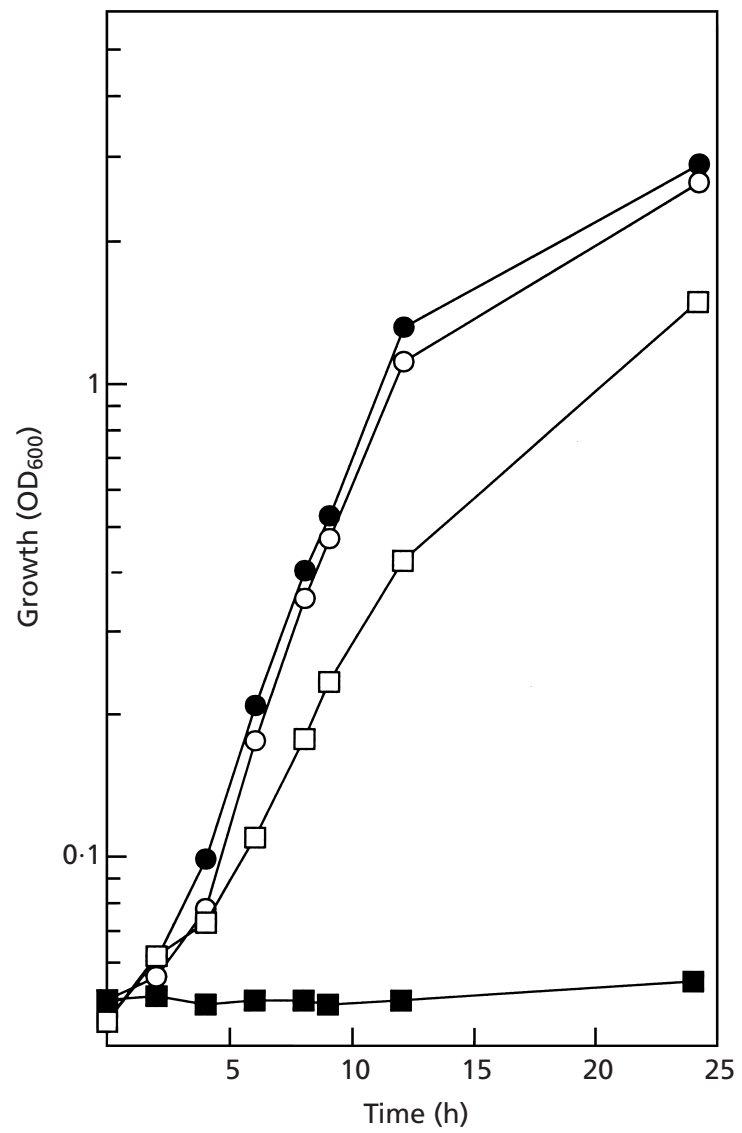

Fig. 4. Growth of strains WM37 (GDH1 GLT1) (@), WM37a (GDH1 g/t1) (O), C4A (gdh1 g/t1) with $38 \mathrm{mM}\left(\mathrm{NH}_{4}\right)_{2} \mathrm{SO}_{4}(\mathbf{\square})$ and C4A (gdh1 glt 1 ) with $0.05 \%$ glutamate without $\left(\mathrm{NH}_{4}\right)_{2} \mathrm{SO}_{4}$ ( $\square$ ).

the evolutionary history of $S$. cerevisiae, but which evolved as a single allele in K. lactis. In addition, it has been proposed, that $S$. cerevisiae genome duplication may have played a role in the evolutionary adaptation of $S$. cerevisiae to fermentative growth (Wolfe \& Shields, 1997). In this regard, it could be speculated that the presence of two NADP-GDH isozymes in $S$. cerevisiae provides a mechanism to equilibrate utilization of 2 oxoglutarate and energy production under fermentative or respiratory conditions. Since K. lactis is a strict aerobe, only able to grow under respiratory conditions, it could be proposed that in this yeast, a single NADPGDH enzyme allows glutamate biosynthesis and thus 2oxoglutarate utilization without compromising energy production.

\section{ACKNOWLEDGEMENTS}

The authors are grateful to Fernando Bastarrachea for his critical review of the manuscript and to Miriam Vazquez Acevedo for technical assistance. The authors are also indebted to Laura Ongay, Marcela Sosa and Guadalupe Codiz from the Molecular Biology Unit of the Instituto de Fisiología
Celular, UNAM, for their help in synthesizing deoxyoligonucleotides and in DNA sequencing.

This work was supported in part by the Dirección General de Asuntos del Personal Académico, Universidad Nacional Autónoma de México (IN212898).

\section{REFERENCES}

Adachi, K. \& Suzuki, I. (1977). Purification and properties of glutamate synthase from Thiobacillus thioparus. J Bacteriol 129, 1173-1182.

Anderson, M. P., Vance, C. P., Heichel, G. H. \& Miller, S. S. (1989). Purification and characterization of NADH-glutamate synthase from alfalfa root nodules. Plant Physiol 90, 351-358.

Avendaño, A., DeLuna, A., Olivera, H., Valenzuela, L. \& González, A. (1997). GDH3 encodes a glutamate dehydrogenase isozyme, a previously unrecognized route for glutamate biosynthesis in Saccharomyces cerevisiae. J Bacteriol 179, 5594-5597.

Barel, I. \& MacDonald, D. W. (1993). Enzyme defects in glutamaterequiring strains of Schizosaccharomyces pombe. FEMS Microbiol Lett 113, 267-272.

Benny, A. G. \& Boland, M. J. (1977). Enzymes of nitrogen metabolism in legume nodules. Purification and properties of NADH-dependent glutamate synthase from lupine nodules. Eur J Biochem 79, 355-362.

Bravo, A. \& Mora, J. (1988). Ammonium assimilation in Rhizobium phaseoli by the glutamine synthetase-glutamate synthase pathway. J Bacteriol 170, 980-984.

Carlberg, I. \& Nordlund, S. (1991). Purification and partial characterization of glutamate synthase from Rhodospirillum rubrum grown under nitrogen-fixing conditions. Biochem J 279, 151-154.

Chen, F. L. \& Cullimore, J. v. (1988). Two isoenzymes of NADHdependent glutamate synthase in root nodules of Phaseolus vulgaris L. Plant Physiol 88, 1411-1417.

Cogoni, C., Valenzuela, L., González-Halphen, D., Olivera, H., Macino, G., Ballario, P. \& González, A. (1995). Saccharomyces cerevisiae has a single glutamate synthase gene coding for a plantlike high-molecular-weight polypeptide. J Bacteriol 177, 792-798.

Doherty, D. (1970). L-Glutamate dehydrogenases (yeast). Methods Enzymol 17, 850-856.

Gietz, R. D. \& Woods, R. A. (1994). High efficiency transformation with lithium acetate. In Molecular Genetics of Yeast: a Practical Approach, pp. 121-134. Oxford: Oxford University Press.

González, A., Membrillo-Hernández, J., Olivera, H., Aranda, C., Macino, G. \& Ballario, P. (1992). Cloning of a yeast gene coding for the glutamate synthase small subunit (GUS2) by complementation of Saccharomyces cerevisiae and Escherichia coli glutamate auxotrophs. Mol Microbiol 6, 301-308.

González-Halphen, D., Lindorfer, M. A. \& Capaldi, R. A. (1988). Subunit arrangement in beef heart complex III. Biochemistry 27, 7021-7031.

Hayakawa, T., Yamaya, T., Kamashi, K. \& Ojima, K. (1992). Purification, characterization and immunological properties of NADH-dependent glutamate synthase from rice cell cultures. Plant Physiol 98, 1317-1322.

Helling, R. B. (1994). Why does Escherichia coli have two primary pathways for synthesis of glutamate? J Bacteriol 176, 4664-4668.

Holmes, A. R., Collings, A., Farnden, K. J. F. \& Sheperd, M. G. (1989). Ammonium assimilation by Candida albicans and other yeasts: evidence for activity of glutamate synthase. J Gen Microbiol 135, 1423-1430. 
Holzer, H. \& Schneider, S. (1957). Anreicherung und Trennung einer DPN-spezifischen und einer TPN-spezifischen Glutaminosaure Dehydrogenase aus Hefe. Biochem Z 328, 361-367.

Hummelt, G. \& Mora, J. (1980). Regulation and function of glutamate synthase in Neurospora crassa. Biochem Biophys Res Commun 96, 1688-1694.

Macheda, L., Hynes, M. J. \& Davis, M. A. (1999). The Aspergillus nidulans gltA gene encoding glutamate synthase is required for ammonium assimilation in the absence of NADP-glutamate dehydrogenase. Curr Genet 34, 467-471.

Maniatis, T., Fritsch, E. F. \& Sambrook, J. (1982) Molecular Cloning. a Laboratory Manual. Cold Spring Harbor, NY: Cold Spring Harbor Laboratory.

Marqués, S., Florencio, F. J. \& Candau, P. (1992). Purification and characterization of the ferredoxin-glutamate synthase from the unicellular cyanobacterium Synechococcus sp. PCC 6301. Eur J Biochem 206, 69-77.

Miflin, B. J., Lea, P. J. \& Wallsgrove, R. M. (1980). The role of glutamine in ammonium assimilation and reassimilation in plants. In Glutamine: Metabolism, Enzymology and Regulation, pp. 213-234. Edited by J. Mora \& R. Palacios. NY: Academic Press.

Miller, R. E. \& Stadtman, E. R. (1972). Glutamate synthase from Escherichia coli. An iron-sulfide flavoprotein. J Biol Chem 247, 7407-7419.

Nasmyth, K. A. \& Reed, S. I. (1980). Isolation of genes by complementation in yeast: molecular cloning of a cell-cycle gene. Proc Natl Acad Sci USA 77, 2119-2123.

Ratti, S., Curti, B., Zanetti, G. \& Galli, E. (1985). Purification and characterization of glutamate synthase from Azospirillum brasilense. J Bacteriol 163, 724-729.

Romero, D. \& Dávila, G. (1986). Genetic and biochemical identification of the glutamate synthase structural gene in Neurospora crassa. J Bacteriol 167, 1043-1047.

Roon, R. J., Even, H. L. \& Larimore, F. (1974). Glutamate synthase: properties of the reduced nicotinamide adenine dinucleotidedependent enzyme from Saccharomyces cerevisiae. J Bacteriol 118, 89-95.

Schägger, H., Link, T. A., Engel, W. D. \& von Jagow, G. (1986). Isolation of the eleven protein subunits of the $b_{1}$ complex from beef heart. Methods Enzymol 126, 224-237.

Schreier, H. J. \& Bernlohr, R. W. (1984). Purification and properties of glutamate synthase from Bacillus licheniformis. J Bacteriol 160, 591-599.

Senior, P. J. (1975). Regulation of nitrogen metabolism in Escherichia coli and Klebsiella aerogenes: studies with the continuous culture technique. J Bacteriol 123, 407-418.

Struhl, K. \& Davis, R. W. (1981). Transcription of the his 3 gene region in Saccharomyces cerevisiae. J Mol Biol 152, 535-552.

Tempest, D. W., Meers, J. L. \& Brown, C. M. (1970). Synthesis of glutamate in Aerobacter aerogenes by a hitherto unknown route. Biochem J 117, 405-407.

Towbin, H., Staehelin, T. \& Gordon, J. (1979). Electrophoretic transfer of proteins from polyacrylamide gels to nitrocellulose sheets : procedure and some applications. Proc Natl Acad Sci USA 76, 4350-4354.

Trotta, P. P., Platzer, K. E. B., Haschemeyer, R. H. \& Meister, A. (1974). Glutamine-binding subunit of glutamate synthase and partial reactions catalyzed by this glutamide amidotransferase. Proc Natl Acad Sci USA 71, 4607-4611.

Tyler, B. (1978). Regulation of the assimilation of nitrogen compounds. Annu Rev Biochem 47, 1127-1162.

Valenzuela, L., Guzmán-León, S., Coria, R., Ramírez, J., Aranda, C. \& González, A. (1995). A NADP-glutamate dehydrogenase mutant of the petit-negative yeast Kluyveromyces lactis uses the glutamine synthethase-glutamate synthase pathway for glutamate biosynthesis. Microbiology 141, 2443-2447.

Valenzuela, L., Ballario, P., Aranda, C., Filetici, P. \& González, A. (1998). Regulation of the expression of GLT1, the gene encoding glutamate synthase in Saccharomyces cerevisiae. J Bacteriol 180, 3533-3540.

Vanoni, M. A., Negri, A., Zanetti, G., Ronchi, S. \& Curti, B. (1990). Structural studies on the subunits of glutamate synthase from Azospirillum brasilense. Biochim Biophys Acta 1039, 374-377.

Wach, A., Brachat, A., Pohlmann, R. \& Philippsen, P. (1994). New heterologous modules for classical or PCR-based gene disruptions in Saccharomyces cerevisiae. Yeast 10, 1793-1808.

Wolfe, K. H. \& Shields, D. C. (1997). Molecular evidence for an ancient duplication of the entire yeast genome. Nature 387, 708-713.

Received 29 June 1999; revised 13 September 1999; accepted 4 October 1999. 